\title{
Effect of Sealing Method and Lighting Candle in Metal Silos on Survival of the Larger Grain Borer, Prostephanus Truncatus, in Stored Maize
}

\author{
Kimani Anne ${ }^{1}$, Tadele Tefera ${ }^{2}$, Olubayo Florence ${ }^{1} \&$ Kilalo Dora ${ }^{1}$ \\ ${ }^{1}$ Department of Plant Science and Crop Protection, Faculty of Agriculture, University of Nairobi, Nairobi, \\ Kenya \\ ${ }^{2}$ International Center of Insect Physiology and Ecology (ICIPE), ILRI Campus, Gurd Shola, Addis Ababa, \\ Ethiopia \\ Correspondence: Tadele Tefera, International Center of Insect Physiology and Ecology (ICIPE), ILRI Campus, \\ Gurd Shola, P.O. Box 5689, Addis Ababa, Ethiopia. Tel: 251-944-168-240. E-mail: ttefera@icipe.org
}

Received: April 15, 2018

doi:10.5539/jas.v10n8p90

\begin{abstract}
The aim of this study was to determine the effect of sealing methods, grain volume and lighting candle in metal silo for the control of Prostephanus truncatus in stored maize. Metal silos with 100 kilograms holding capacity were loaded with 90 kilograms of grain, in-let and out-let were covered with lids and sealed either with rubber band, grease, rubber band combined with grease and lid without sealing (control). The control suffered highest grain damage of $6.6 \%$ and weight loss of $1.9 \%$ compared to metal silo sealed using rubber band combined with grease which had grain damage $4.5 \%$ and weight loss $0.6 \%$, thirty-five days after storage. Metal silo sealed with rubber band combined with grease had significantly higher $\mathrm{CO}_{2}$ level of $2.1 \% \mathrm{v} / \mathrm{v}$ than the control $0.5 \% \mathrm{v} / \mathrm{v}$. In a separate experiment, metal silos with: 90 kilograms of grain, with and without lighted candle; 45 kilograms of grain, with and without lighted candle and a polypropylene bag with 90 kilograms of grain were compared. Ninety days after storage, grain stored in all metal silos regardless of grain volume and candle lighting suffered the least weight loss $0.2 \%$ to $1.1 \%$, and damage $4.1 \%$ to $10.5 \%$ compared to grain in polypropylene bags which had the highest loss $7.3 \%$ to $25.3 \%$ and damage, $28.9 \%$ to $37.5 \%$. All metal silos irrespective of grain volume and candle lighting during storage had $100 \%$ insect mortality while in control the number of live $P$. truncatus increased from 100 to 1786, ninety days after storage. Proper sealing of metal silo with either rubber band or grease and use of lighted candle effectively controlled $P$. truncatus in stored maize irrespective of grain volume.
\end{abstract}

Keywords: carbon dioxide, maize, metal silo, post-harvest loss, Prostephanus truncatus

\section{Introduction}

Postharvest losses estimated at 30\% are because of postharvest insect pests, poor and ineffective storage technologies accessible at all levels along the maize value chain (Songa \& Irungu, 2010). Larger grain borer, Prostephanus truncatus (Horn) is the most serious pest of on-farm stored maize grain causing over 30\% weight loss (Boxall, 2002; Mallya, 1992). P. truncatus caused 67\% weight loss compared to 6.9\% caused by Sitophillus zeamais in a period of 90 days in a laboratory experiment (Tefera et al., 2011b). Chemical, biological and cultural methods have been explored to manage $P$. truncatus but none is efficient and cost effective (De Groote et al., 2013). Pesticides have been used to manage $P$. truncatus but have negative effects on human health environment and non-target organisms (Sambarashe et al., 2013; Musa et al., 2009). Pesticides are costly and require frequent application thus farmers who cannot afford pesticides are forced to dispose their produce soon after harvest at lower market prices (Kimenju et al., 2009). Globally, metal silos have been promoted as alternatives for pesticide use in managing storage pests (Tefera et al., 2011a; De Groote et al., 2013; Quezada et al., 2006). They are cheap, effective and environmental friendly with a shelf-life of over 10 years (Hellin \& Kanampiu, 2008; CIMMYT, 2009). They allow storage of grain for long periods while maintaining grain quality (Tefera et al., 2011a; FAO, 2008).

In sub-Saharan Africa, small scale farmers use their maize as a source of food and income. They sell part of their grain to meet their various needs at different times of the year, affecting the volume of the grain left in the metal 
silo. Adoption of metal silos to store on-farm maize will ensure food and income security to small holder farmers who can store their maize for a longer period and sell their produce at higher prices in the market. For effective control of storage pests, metal silos should be properly managed during storage. A survey done in Central America showed that farmers incurred losses of up to $20 \%$ due to poor silo management practices (POSTCOSECHA, 2011). In Africa, metal silo is being promoted with proper sealing and depletion of oxygen with locally available materials to maintain its hermetic condition. Rubber bands derived from worn-out vehicle tyres and wax candle burning are employed as sealing agent and oxygen deplete, respectively. There is, however, no empirical evidence so far on the efficacy lighting candle and rubber sealing on the level of damage and loss of grain in metal silos. We argue that the type of materials used to seal the in-let and out-let lids of the metal silo may affect the effectiveness of the metal silo to control storage pests and maintain grain quality. This paper, therefore, reports on different methods of sealing and lighting candle in metal silos on P. truncatus survival and grain in stored maize.

\section{Materials and Methods}

\subsection{Experimental Site}

The on-station experiment was conducted at Kenya Agricultural and Livestock Research Organization (KALRO) and International Maize and Wheat Improvement Center (CIMMYT) Kiboko postharvest insect pest laboratory (latitude $2^{\circ} 1$ 'S, longitude $37^{\circ} 7^{\prime} \mathrm{E}$ and altitude $975 \mathrm{~m}$ above sea level) at ambient room conditions with mean temperature of $26 \pm 2{ }^{\circ} \mathrm{C}$ and relative humidity of $57 \pm 5 \%$.

\subsection{Grain Preparation}

Freshly harvested hybrid maize grains were bought from farmers in the area and used for the experiment. For insects rearing in the laboratory, freshly harvested hybrid H513 was obtained for KALRO/CIMMYT kiboko station farm. The grains were cleaned by sieving to remove dirt, dust, fine materials, mouldy and shrivelled kernels and dried in the sun to $10-12 \%$ moisture content. It was fumigated with Phostoxin tablet (55\% aluminum phosphide, $45.0 \%$ inert material) in sealed plastic drums for seven days to disinfest it from any possible sources of infestation before the start of the experiment and use in the laboratory. After fumigation, the grain was thoroughly mixed and aerated through sieving 24 hours before use to avoid residual effect of phosphine gas in the grain.

\subsection{Insect Culture}

Adult $P$. truncatus were obtained from KALRO/CIMMYT Kiboko postharvest insect pest laboratory where the experiment was conducted. They were reared on freshly harvested maize grain of susceptible hybrid $\mathrm{H} 513$ in the laboratory, where four hundred grams of the grain was put in 1.5 litre glass jars covered with perforated lids. Two hundred unsexed $P$. truncatus adults were introduced into each glass jar. After ovipositing for ten days, all adult insects were removed by sieving glass jar contents using 4.7 and $1.0 \mathrm{~mm}$ sieves (Endecotts Limited, UK) to separate the dust, grain and insects. The grain where the adults had oviposited was kept in clean aerated 1.5 litre glass jars and monitored daily for progeny emergence. Those that emerged on the same day were transferred to fresh grain in 1.5 litre glass jars and kept in the incubation room at $28 \pm 2{ }^{\circ} \mathrm{C}, 65 \pm 5 \%$ relative humidity and in a 12:12, light: dark regime until sufficient number of insects were obtained. Ten-day old adult $P$. truncatus were used in the experiment (Tefera et al., 2010).

\subsection{Treatments}

Metal silos with a holding capacity of $100 \mathrm{~kg}$, made of galvanized metal sheet of 24-inch gauge fabricated locally by trained tinsmith were used (Figure 1). The joints were sealed by capillary soldering using tin-lead $(50 / 50)$ solder and a soldering iron to ensure that they were airtight (CIMMYT, 2011). The metal silos were designed to have a knob that was fitted five centimeters from the neck of the metal silo and covered with an elastic rubber cork. 


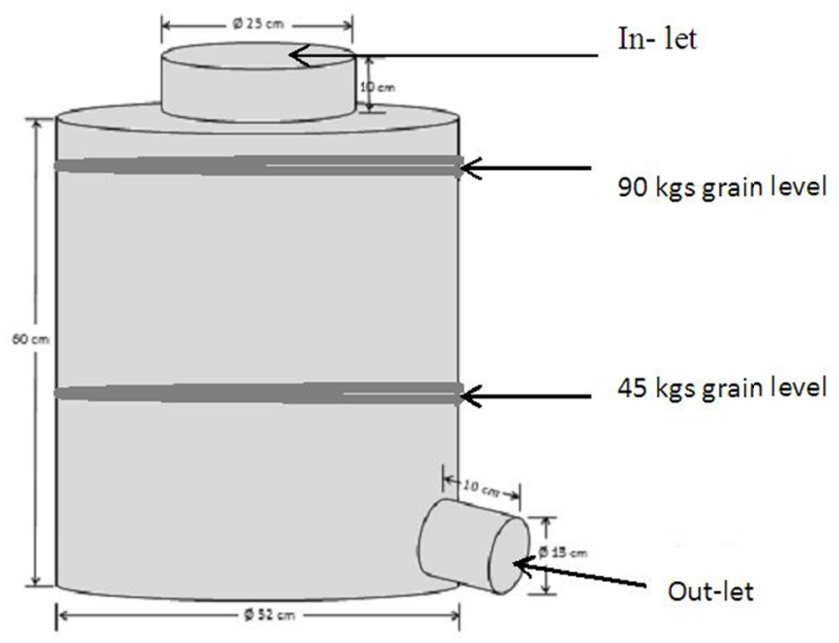

Figure 1. Metal silo with a holding capacity of $100 \mathrm{~kg}$ of maize grain

\subsection{Evaluation of Different Sealing Methods on P. truncatus Damage and Loss to Stored Maize Grain}

Four methods of sealing metal silos were used. These were: rubber band, grease, rubber band combined with grease and control without sealing. Metal silos of $100 \mathrm{~kg}$ full grain holding capacity were loaded with 90 kilograms of grain. One hundred, unsexed 10-day old adult $P$. truncatus were artificially introduced into each metal silo. A candle was placed on top of the grain in the metal silo, the candle was lit, the in-let and outlet lids of the metal silo were sealed using rubber band, grease, rubber band combined with grease and left without sealing (control). The aim of using candle burning was to deplete oxygen inside the metal silo (Tefera et al., 2011a). The metal silos were placed on wooden pallets $(15 \mathrm{~cm}$ high), arranged in a completely randomized design with four metal silos per treatment and stored for 35 days in a room roofed with corrugated iron sheets at ambient temperature of $27 \pm 2{ }^{\circ} \mathrm{C}$ and $58 \pm 5 \%$ relative humidity.

2.6 Effect of Grain Volume and Lighted Candle in Metal Silos on Gas Concentration and Grain Damage by P. truncatus in Stored Maize

Metal silos of $100 \mathrm{~kg}$ grain holding capacity and polypropylene bags of $90 \mathrm{~kg}$ holding capacity were used. Five treatments were used. These were: metal silo loaded with $90 \mathrm{~kg}$ of grain and a lighted candle; metal silo loaded with $45 \mathrm{~kg}$ of grain and a lighted candle; metal silo loaded with $90 \mathrm{~kg}$ of grain without lighted candle; metal silo loaded with $45 \mathrm{~kg}$ of grain without lighted candle and polypropylene woven bag (control) loaded with $90 \mathrm{~kg}$ of grain and tied tightly with sisal rope were compared. In each treatment, an aerated 1.5 liter glass jar containing four hundred (400) grams of grain was placed on top of the grain in each container. One hundred newly emerged unsexed 10-day old adult $P$. truncatus were artificially introduced into each treatment. Besides, one hundred $P$. truncatus were artificially introduced into the grain inside each glass jar. The metal silo lids sealed with rubber band and the bags were tied with rope. All treatments (silos and bags) were placed on wooden pallets $(15 \mathrm{~cm}$ high), arranged in a completely randomized design with four metal silos and four bags per treatment. They were kept for ninety days in a room roofed with corrugated iron sheet at ambient temperature of $27 \pm 2{ }^{\circ} \mathrm{C}$ and $58 \pm 5 \%$ relative humidity.

\subsection{Sample Collection}

Grain samples were collected from each metal silo and polypropylene bag using a compartmentalized double tube sampling spear (Seedburo Equipment, Company Chicago, USA) at the start and end of the experiment as described by De Groote et al. (2013). The samples from each metal silo and polypropylene bag were put in separate trays and thoroughly mixed, $1 \mathrm{~kg}$ of the sample from each treatment was drawn randomly and used to assess grain damage and weight loss.

\subsection{Data Collection}

Oxygen and carbon dioxide levels were measured in the headspace of the metal silos and in the polypropylene bags every week. All metal silos were designed to have a knob covered with an elastic rubber cork through which gas levels were measured using portable Mocon ${ }^{\circledR}$ PAC CHECK Model 325 Headspace analyzer (Mocon, 
Minneapolis, MN, USA) fitted with a 1.15" 20 -gauge needle for sampling through rubber septa. In the polypropylene bags, the needle was pricked through the bag into the grain and data taken.

The one-kilogram sample collected from each treatment as described above was used to assess grain damage and weight loss in each metal silo and polypropylene bag. The samples and the glass jar content from each treatment were separately sieved using $4.7 \mathrm{~mm}$ and $1.0 \mathrm{~mm}$ sieves (Endecotts Limited, UK) to separate the grains, insects (live and dead) and dust (Tefera et al., 2011b). The total number of damaged (holed and windowed) and undamaged grains were counted and their weight recorded. Grain damage was expressed as a proportion of damaged grain over the total number of grains sampled (Tefera et al., 2011b). Percent weight loss was determined using the count and weight method (Gwinner et al., 1996);

$$
\text { Weight } l o s s \%=\frac{(W u \times N d)-(W d \times N u)}{W u \times(N d+N u)} \times 100
$$

Where, $W u$ : weight of undamaged grain, $N u$ : number of undamaged grain, $W d$ : Weight of damaged kernel and $N d$ : Number of damaged kernels.

\subsection{Statistical Analysis}

Data analysis was done using statistical software GenStat $14^{\text {th }}$ Edition. Prior to statistical analysis, Percent grain damage and weight loss were angular-transformed (arcsine $\sqrt{\text { proportion }}$ ), number of live insets, dead insects and F1 progeny were log-transformed, to stabilize the variances. Oxygen and carbon dioxide levels were not transformed. One-way analysis of variance (ANOVA) was used to analyze the data and the means separated using Fisher's Protected LSD test at 5\% probability level. The results presented in tables and figures are untransformed values.

\section{Results}

3.1 Evaluation of Different Sealing Methods of Metal Silo on Gas Concentration, Grain Damage and Loss Caused by P. truncatus in Stored Maize

\subsubsection{Oxygen and Carbon Dioxide Level}

Sealing methods significantly $\left(\mathrm{F}_{3,12}=0.001 ; \mathrm{p}<0.05\right)$ affected carbon dioxide and oxygen levels after thirty-five days of storage. Carbon dioxide and oxygen level showed an opposite trend in the metal silo sealed with different sealing methods (Figure 2 and 3). The metal silo sealed with rubber band combined with grease had the least $\mathrm{O}_{2}$ followed by metal silo sealed with rubber band, grease and the control while the opposite was true for $\mathrm{CO}_{2}$.

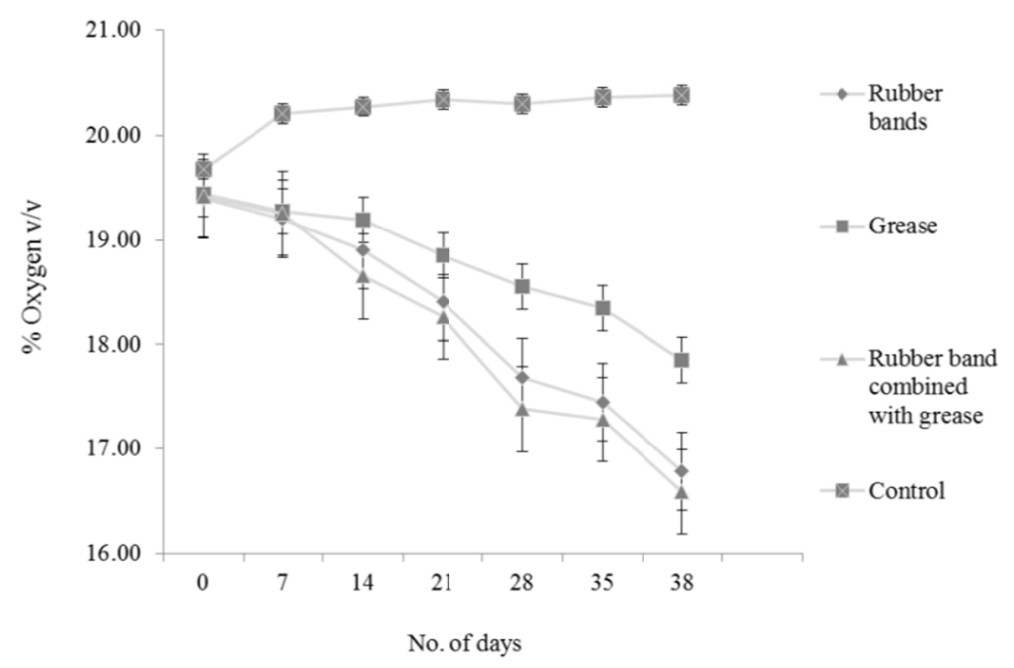

Figure 2. Weekly oxygen trend in metal silos filled with maize grain and sealed with different sealing methods 


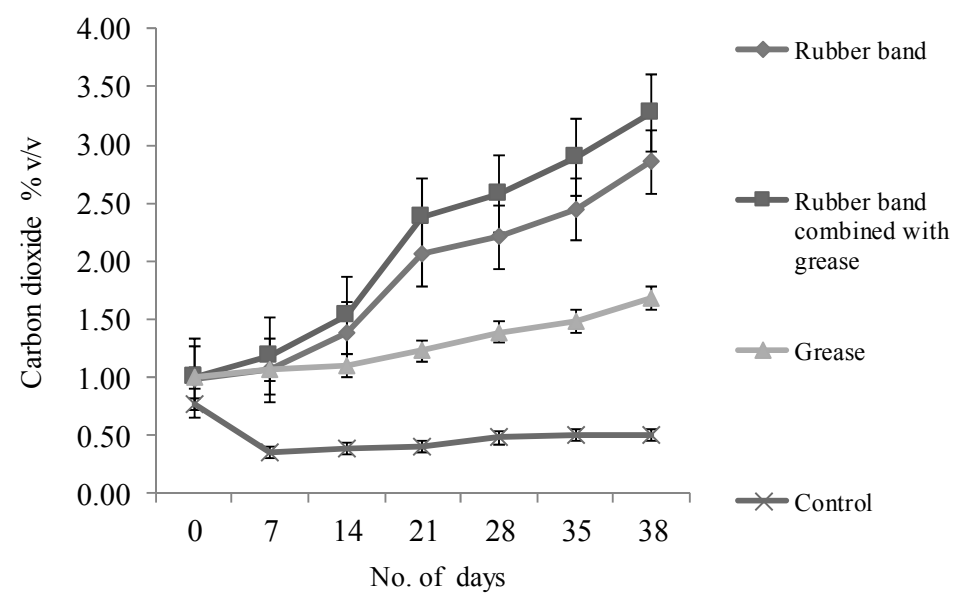

Figure 3. Weekly carbon dioxide trend in metal silos filled with maize grain and sealed with different sealing methods

\subsubsection{Percent Grain Damage and Weight Loss}

Sealing methods significantly affected percent weight loss $\left(\mathrm{F}_{3,12}=0.015 ; \mathrm{P}<0.05\right)$ compared to the control while grain damage $\left(\mathrm{F}_{3,12}=0.25 ; \mathrm{P}<0.05\right)$ did not differ significantly. Grains stored in the control suffered the highest weight loss $(1.9 \%)$ and damage $(6.6 \%)$ compared to metal silo sealed with rubber band combined with grease which had the least weight loss (0.6\%) and grain damage, 35 days after storage (4.5\%) (Figures 4 and 5 ).

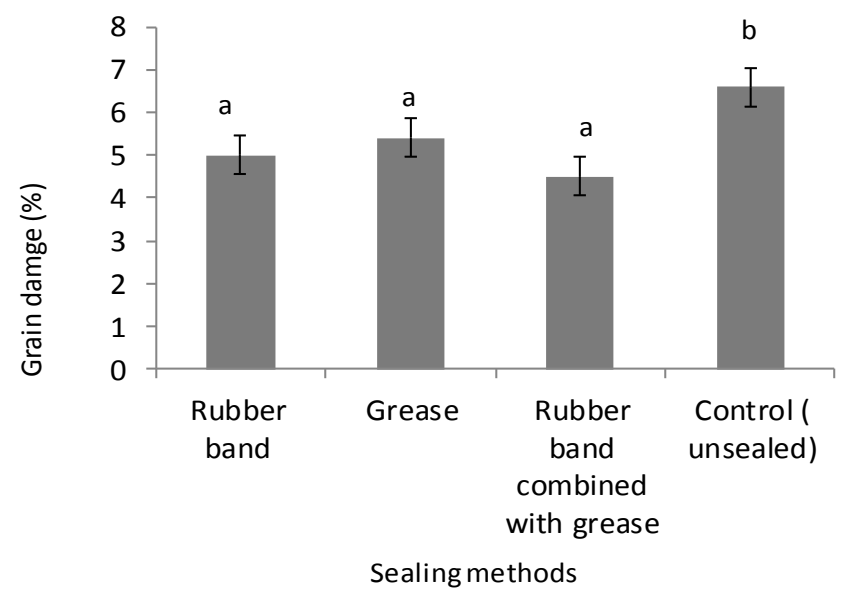

Figure 4. Grain damage (\%) in metal silo sealed with different sealing methods

Note. The bars with different letter (s) across the graph are significantly different at $\mathrm{P}<0.05$. 


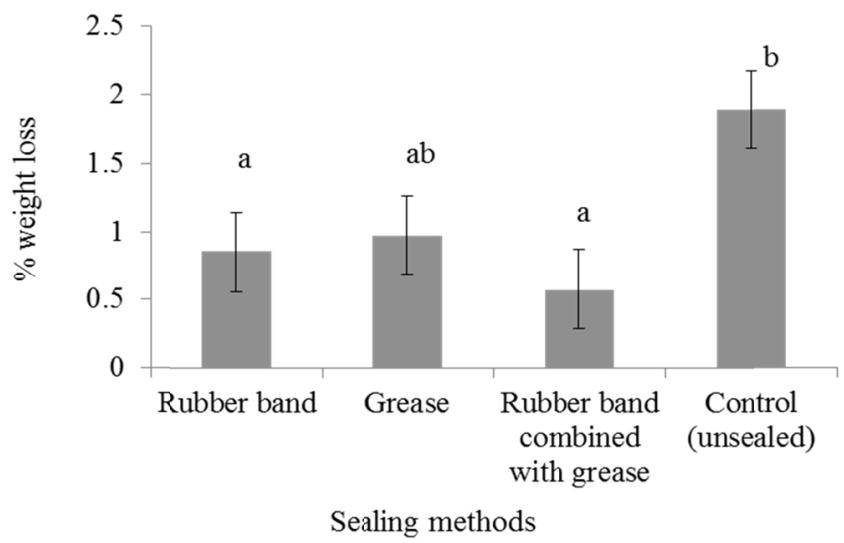

Figure 5. Weight loss (\%) incurred in metal silos sealed with different sealing methods

Note. The bars with different letter (s) across the graph are significantly different at $\mathrm{P}<0.05$.

\subsection{Effect of Grain Volume and Lighted Candle in Metal Silos on Gas Concentration and Damage by P. truncatus in Stored Maize}

\subsubsection{Oxygen and Carbon Dioxide Level}

Grain volume and use of lighted candle significantly $\left(\mathrm{F}_{4,15}=0.001 ; \mathrm{P}<0.05\right)$ affected $\mathrm{O}_{2}$ and $\mathrm{CO}_{2}$ level in metal silos after ninety days of storage (Table 1). The metal silos filled with $90 \mathrm{~kg}$ and $45 \mathrm{~kg}$ grain with lighted candle had the least level of $\mathrm{O}_{2}$ (about 17\%) and the highest level of $\mathrm{CO}_{2}$ (about 3\%). An opposite trend was observed in a metal silo filled with $90 \mathrm{~kg}$ and $45 \mathrm{~kg}$ of grain without lighted candle $\left(>20 \% \mathrm{O}_{2}\right.$ and $\left.<0.5 \% \mathrm{CO}_{2}\right)$. Polypropylene bag, however, had the highest $\mathrm{O}_{2}(20.94 \%)$ and least $\mathrm{CO}_{2}(0.05 \%)$ (Table 1$)$.

Table 1. Mean oxygen and carbon dioxide level in metal silos and polypropylene bags with filled maize grain and infested with $P$. truncatus 90 days after storage

\begin{tabular}{lll}
\hline Treatments & Oxygen (\%) & Carbon dioxide (\%) \\
\hline Metal silo with $90 \mathrm{~kg}$ and lighted candle & $17.9 \pm 0.4 \mathrm{a}$ & $3.0 \pm 0.6 \mathrm{a}$ \\
Metal silo with $45 \mathrm{~kg}$ and lighted candle & $17.7 \pm 0.4 \mathrm{~b}$ & $3.3 \pm 0.5 \mathrm{~b}$ \\
Metal silo with $90 \mathrm{~kg}$ without candle & $20.3 \pm 0.5 \mathrm{c}$ & $0.6 \pm 0.01 \mathrm{c}$ \\
Metal silo with $45 \mathrm{~kg}$ without candle & $20.5 \pm 0.5 \mathrm{c}$ & $0.4 \pm 0.02 \mathrm{~d}$ \\
Polypropylene bag (control) & $20.9 \pm 0.5 \mathrm{~d}$ & $0.05 \pm 0.01 \mathrm{e}$ \\
\hline
\end{tabular}

Note. Means followed by the same letters within a column are not significantly different.

\subsubsection{Percent Grain Damage and Weight Loss}

Grain volume and use of lighted candle significantly $\left(\mathrm{F}_{4,15}=0.001 ; \mathrm{P}<0.05\right)$ affected grain damage and weight loss in glass jars, metal silos and polypropylene bags (Table 2$)$. The least weight loss $(0.3 \%$ to $1.1 \%)$ and grain damage ( $4.1 \%$ to $10.5 \%)$ were recorded in the metal silos regardless of grain volume and candle lighting (Table 2). Grain stored in polypropylene bags, however, suffered the highest percent weight loss $(7.3 \%$ to $25.3 \%)$ and percent damage ( $28.9 \%$ to $37.5 \%) 90$ days after storage.

Table 2. Per cent grain damage and weight loss caused by $P$. truncatus in grain stored in glass jars, metal silos and polypropylene, 90 days after storage

\begin{tabular}{llllll}
\hline \multirow{2}{*}{ Treatments } & \multicolumn{2}{c}{ Glass jars } & & \multicolumn{2}{c}{ Metal silos \& polypropylene bag } \\
\cline { 2 - 3 } \cline { 5 - 6 } \cline { 5 - 6 } & Weight loss\% & Damage\% & & Weight loss\% & Damage\% \\
\hline Metal silo with 90 kg grain and lighted candle & $0.3 \pm 0.03 \mathrm{a}$ & $4.1 \pm 0.2 \mathrm{a}$ & & $0.4 \pm 0.02 \mathrm{a}$ & $6.3 \pm 0.2 \mathrm{a}$ \\
Metal silo with 45 kg grain and lighted candle & $0.5 \pm 0.04 \mathrm{~b}$ & $4.2 \pm 0.2 \mathrm{a}$ & & $0.2 \pm 0.01 \mathrm{a}$ & $6.3 \pm 0.2 \mathrm{a}$ \\
Metal silo with 90 kg grain without candle & $0.6 \pm 0.05 \mathrm{c}$ & $5.8 \pm 0.2 \mathrm{~b}$ & & $1.1 \pm 0.04 \mathrm{~b}$ & $8.4 \pm 0.2 \mathrm{~b}$ \\
Metal silo with 45 kg grain without candle & $0.7 \pm 0.05 \mathrm{~d}$ & $6.8 \pm 0.2 \mathrm{~b}$ & & $1.0 \pm 0.05 \mathrm{~b}$ & $10.5 \pm 0.3 \mathrm{c}$ \\
Polypropylene bag (control) & $25.3 \pm 0.5 \mathrm{e}$ & $37.5 \pm 06 \mathrm{c}$ & & $7.3 \pm 0.3 \mathrm{c}$ & $28.9 \pm 0.5 \mathrm{~d}$ \\
\hline
\end{tabular}

Note. Means followed by the same letters within a column are not significantly different. 


\subsubsection{P. truncatus Mortality and $\mathrm{F}_{1}$ Progeny Emergence}

Significant differences were observed in $P$. truncatus mortality $\left(\mathrm{F}_{4,15}=0.001 ; \mathrm{P}<0.05\right)$ and $\mathrm{F}_{1}$ progeny emergence $\left(\mathrm{F}_{4,15}=0.001 ; \mathrm{P}<0.05\right)$ in all treatments after storing maize for ninety days (Table 3$)$. There was $100 \%$ P. truncatus mortality in all glass jars as well as in the metal silos with and without lighted candle irrespective of grain volume. In control, the number of live P. truncatus increased from 100 to 1537 in the glass jar and increased from 100 to 1786 in the polypropylene bag.

The control had the highest mean of $F_{1}$ progeny (56) that emerged from the grain in the glass jar and $F_{1}$ progeny (191) which emerged from the grain in the polypropylene bag after incubating for 56 days (Table 3). About 4 to $7, F_{1}$ progeny emerged from grain stored in the metal silo without lighted candle irrespective of the grain volume. No $F_{1}$ progeny emerged from grains stored in metal silo with lighted candle.

Table 3. Mean number of dead and live P. truncatus and $\mathrm{F}_{1}$ progeny emerged in maize grain stored in glass jars, metal silos and polypropylene bags for 90 days

\begin{tabular}{|c|c|c|c|c|c|c|}
\hline \multirow[b]{2}{*}{ Treatments } & \multicolumn{3}{|c|}{ Glass jars } & \multicolumn{3}{|c|}{ Metal silos \& Polypropylene bag (control) } \\
\hline & $\begin{array}{l}\text { No. of } \\
\text { dead LGB }\end{array}$ & $\begin{array}{l}\text { No. of } \\
\text { live LGB }\end{array}$ & $\begin{array}{l}\text { No. of } \\
F_{1} \text { progeny }\end{array}$ & \% Mortality & $\begin{array}{l}\text { No. of } \\
\text { live LGB }\end{array}$ & $\begin{array}{l}\text { No. of } \\
F_{1} \text { progeny }\end{array}$ \\
\hline Metal silo with $90 \mathrm{~kg}$ grain and lighted candle & $100 \pm 0.2 \mathrm{a}$ & $0 \pm 0.03 \mathrm{a}$ & $0 \pm 0.01 \mathrm{a}$ & $100 \pm 0.01 \mathrm{a}$ & $0 \pm 0.02 \mathrm{a}$ & $0 \pm 0.01 \mathrm{a}$ \\
\hline Metal silo with $45 \mathrm{~kg}$ grain and lighted candle & $100 \pm 0.2 \mathrm{a}$ & $0 \pm 0.03 \mathrm{a}$ & $0 \pm 0.01 \mathrm{a}$ & $100 \pm 0.01 \mathrm{a}$ & $0 \pm 0.02 \mathrm{a}$ & $0 \pm 0.01 \mathrm{a}$ \\
\hline Metal silo with $90 \mathrm{~kg}$ grain without candle & $100 \pm 0.2 \mathrm{a}$ & $0 \pm 0.03 \mathrm{a}$ & $0 \pm 0.01 \mathrm{a}$ & $100 \pm 0.01 \mathrm{a}$ & $0 \pm 0.02 \mathrm{a}$ & $6 \pm 0.04 \mathrm{~b}$ \\
\hline Metal silo with $45 \mathrm{~kg}$ grain without candle & $100 \pm 0.2 \mathrm{a}$ & $0 \pm 0.03 \mathrm{a}$ & $0 \pm 0.01 \mathrm{a}$ & $100 \pm 0.01 \mathrm{a}$ & $0 \pm 0.02 \mathrm{a}$ & $7 \pm 0.04 \mathrm{~b}$ \\
\hline Polypropylene bag (control) & $247 \pm 0.03 b$ & $1537 \pm 3.1 \mathrm{~b}$ & $56 \pm 1.0 \mathrm{~d}$ & $534 \pm 0.06 \mathrm{~b}$ & $1786 \pm 3.1 \mathrm{~b}$ & $191 \pm 2.1 \mathrm{c}$ \\
\hline
\end{tabular}

Note. Means followed by the same letters within a column are not significantly different.

\section{Discussion}

In this study, oxygen level in metal silos sealed with rubber band, rubber band combined with grease and grease alone reduced below the normal level $(21 \%)$ in the atmosphere while carbon dioxide increased with time to over 10 times the normal $\mathrm{CO}_{2}$ level $(0.038 \%)$ in the atmosphere. Calderon and Navarro (1980), and Murdock et al. (2012) reported metabolic activities of the insects, microorganisms and grain respiration in hermetic storage utilize oxygen and increase carbon dioxide production leading to insect mortality due to desiccation. In this study, production of $\mathrm{CO}_{2}$ in the metal silos was because of using lighted candle inside the metal silos in combination with metabolic activities of the insect and grain respiration. The level of oxygen consumed and carbon dioxide produced in hermetic containers is dependent on the level of insect infestation and grain respiration. Navarro et al. (1994) reported oxygen levels of below $10 \% \mathrm{v} / \mathrm{v}$ in 180 days when 2 insects $/ \mathrm{kg}$ were used and $5 \%$ in less than 90 days when 8 insects $/ \mathrm{kg}$ of grain in a liner with an oxygen ingress rate of $0.24 \% /$ day. Baoua et al. (2012b) in his study reported a reduction of oxygen to $3 \%$ and production of $5 \%$ carbon dioxide when an average of 24 insect $/ \mathrm{kg}$ of grain was used in Purdue Improved Cowpeas Storage (PICS) bags. It was observed in this study that the level of $\mathrm{O}_{2}$ depletion and $\mathrm{CO}_{2}$ production was low contrary to what Baoua et al. (2012b) reported in PICs bags. An insect infestation level of 1 insect $/ \mathrm{kg}$ of grain was used in this study to mimic low levels of insect infestation that may occur naturally when the crop is still in the field. This could have contributed to the slow rate of $\mathrm{O}_{2}$ depletion and $\mathrm{CO}_{2}$ production in metal silos. During grain respiration, maize with high moisture content $(23 \%)$ produced higher $\mathrm{CO}_{2}$ compared to when the moisture content was $15 \%$ because of high respiration rate (Ragai \& Loomis, 1954; Reuss et al., 1994). In this study, the moisture content of the grain was $10-12 \%$ and this could have lowered the rate of grain respiration and insect metabolism leading to less oxygen consumption and carbon dioxide production during storage.

A negative correlation between gas composition (low oxygen and high carbon dioxide levels), weight loss and grain damage was observed in the metal silos. Metal silos sealed with rubber band, grease and rubber band combined with grease had lower weight losses and grain damage compared to the unsealed metal silos (control). This could be attributed to slowed insect feeding activity when $\mathrm{O}_{2}$ level in the sealed metal silos fell below the normal level (21\%) in comparison with the control. Murdock et al. (2012), in their study observed slowed insect feeding activity when oxygen fell below ambient level and completely ceased when oxygen fell to $1-4 \%$ in PICS bags. In this study, grain damage was relatively higher than normal phenomena that could be explained by the fact that this maize was bought from different farmers who handled their grain differently and hence some had high numbers of damaged kernels including broken kernels. However, it is worth noting that the number of 
insect damaged kernels (holed and windowed) in the sealed metal silos was far much lower compared to those in the control at the end of the experiment.

Use of lighted candle inside the metal silo during grain storage assisted in quickly depleting oxygen and elevating carbon dioxide level in metal silos. The metal silos with lighted candle had higher $\mathrm{CO}_{2}$ and lower $\mathrm{O}_{2}$ levels compared to the metal silos without candle, both in preliminary and the main trial. The higher level of $\mathrm{CO}_{2}$ in metal silos with lighted candle was because of combustion, insect metabolic activity and grain respiration compared to the metal silos without lighted candle where $\mathrm{CO}_{2}$ production depended on grain respiration and insect metabolic activities only. During combustion, oxygen in the metal silo was used as carbon dioxide and water were being produced; $\mathrm{C}_{3} \mathrm{H}_{8}+5 \mathrm{O}_{2} \rightarrow 3 \mathrm{CO}_{2}+4 \mathrm{H}_{2} \mathrm{O}+$ Heat and light. The presence of water which was produced during combustion raised humidity in the grain which in turn increased biological activities in the metal silo depleting $\mathrm{O}_{2}$ faster and raising $\mathrm{CO}_{2}$ level than in the metal silos without candle and the control. Studies by Ragai and Loomis (1954), and Reuss et al. (1994), indicated respiration rate is higher in the grain with higher moisture content than in low moisture content, thus raising the amount of $\mathrm{CO}_{2}$ which was produced. Metal silo with $45 \mathrm{~kg}$ had less volume of grain and more oxygen in the headspace of the container than that with $90 \mathrm{~kg}$ hence higher $\mathrm{CO}_{2}$ was produced during combustion.

Percent weight loss and grain damage in metal silos with lighted candle was lower than in metal silos without candle. This may be attributed to high $\mathrm{CO}_{2}$ and low $\mathrm{O}_{2}$ level which slowed down insect feeding in metal silos with lighted candle compared to the metal silos without candle and the polypropylene bags. Murdock et al. (2012) reported that insect feeding was slowed down when oxygen fallen below ambient level and the insects practically ceased feeding when it fell to $1-4 \%$. Although in this study oxygen and carbon dioxide levels did not reach those reported by Murdock et al. (2012) in PICS bags, damage by insects in the metal silos was lower compared to the control (polypropylene bag). Grain volume and use of lighted candle in the metal silos affected LGB insects and hence the level of grain damage. Metal silos without lighted candle had the higher damage level than those with lighted candle after ninety days of storage. Similarly, the level of damage was slightly higher in the metal silos with $45 \mathrm{~kg}$ of grain compared to those with $90 \mathrm{~kg}$. It is probably that, there was a slower rate in the change of gas composition in metal silos without candle, thus giving the insects more time to feed than in metal silos with lighted candle. In metal silos with less volume, there was more oxygen in the headspace and this took time to deplete thus enabling the insects to feed more than in the higher grain volume. This agrees with similar observations by Pattison (1970), and Navarro et al. (1994) where they reported that, partially filled drums have large headspace and insects can cause grain damage before oxygen levels are reduced to a level that would prevent insect development. Hermetic containers should be filled as close to the brim as possible to avoid large air space to grain ratio which may not reduce oxygen to levels that can effectively control pest populations (USDA, 2009). The number of insect damaged grains was low in the metal silos with lighted candle than those without lighted candle. In the control (polypropylene bag), grain damage was highest with Sitophilus zeamais and Tribolium casteum invading the grain after 90 days of storage. The invasion was a result of the insects gaining access to the grain when the polypropylene bag was damaged by the larger grain borer.

Use of lighted candle in the metal silos during storage affected the levels of $\mathrm{CO}_{2}$ and $\mathrm{O}_{2}$ in the metal silos quickly killing the adult females before they could oviposit the eggs. Hence no progeny emerged in the metal silos with lighted candle after exposing the grain to favourable temperature of $28 \pm 2{ }^{\circ} \mathrm{C}$, relative humidity of $65 \pm 5 \%$ in the incubation room. Synergistic effect of low $\mathrm{O}_{2}$ and high $\mathrm{CO}_{2}$ in hermetic containers deprives insects of air and water leading to their death (Murdock et al., 2012). Irrespective of grain volume, change in gas composition inside the metal silos led to $100 \%$ insect mortality after ninety days of storage. In this study, it is likely that there was carbon monoxide gas produced during incomplete combustion that may have occurred when the candle was lit in an enclosed metal silo. In other studies, the presence of carbon monoxide gas in the head space of hermetic containers used to store grain and legumes have been reported (Reuss \& Pratt, 2001; Whittle et al., 1994). Contrary to the metal silos with lighted candle, $F_{1}$ progeny emerged in metal silos without candle after the grain was exposed to temperature of $28 \pm 2{ }^{\circ} \mathrm{C}$ and relative humidity of $65 \pm 5 \%$ in the incubation room (Tefera et al., 2011b). It is supposed that there was a slow rate of $\mathrm{CO}_{2}$ which was produced in metal silos without lighted candle because of metabolic activities of the insects and the respiration of grain compared to the $\mathrm{CO}_{2}$ which was produced by the lighted candle, metabolic activities of the insects and the respiration of the grain in the metal silos with lighted candle. Thus, enabling the adult females to oviposit the eggs in the metal silos without lighted candle before they were exposed to the lethal levels of $\mathrm{CO}_{2}$ which was produced during storage. Studies by Murdock et al. (2012), and Baoua et al. (2012) reported that although Callosobruchus maculatus adults died when the $\mathrm{CO}_{2}$ level increased, the eggs were tolerant to low $\mathrm{O}_{2}$ and high $\mathrm{CO}_{2}$ levels. In this case, the eggs could 
survive the lethal conditions and developed when they were exposed to favourable temperature of $28 \pm 2{ }^{\circ} \mathrm{C}$ and relative humidity of $65 \pm 5 \%$ during incubation.

\section{Conclusion}

Irrespective of grain volume, metal silos could preserve grain quality and effectively controlled P. truncatus without use of insecticides. Use of lighted candle in the metal silos enhanced insect mortality by rapidly lowering oxygen and elevating carbon dioxide at the beginning of storage leading to little or no damage due to insects.

\section{Acknowledgments}

This work was supported by the Swiss Agency for Development and Cooperation.

\section{References}

Baoua, I. B., Margam, V., Amadou, L., \& Murdock, L. L. (2012). Performance of triple bagging hermetic technology for postharvest storage of cowpea grain in Niger. Journal of Stored Products Research, 51, 81-85. https://doi.org/10.1016/j.jspr.2012.07.003

Boxall, R. A. (2002). Damage and loss caused by the larger grain borer Prostephanus truncatus. Integrated Pest Management Reviews, 7, 105-121. https://doi.org/10.1023/A:1026397115946

Calderon, M., \& Navarro, S. (1980). Synergistic effect of $\mathrm{CO}_{2}$ and $\mathrm{O}_{2}$ mixtures on two stored grain insect pests. In J. Shejbal (Ed.), Controlled Atmosphere Storage of Grains (pp. 79-84). Amsterdam, Elsevier. https://doi.org/10.1016/B978-0-444-41939-2.50013-9

CIMMYT (International Maize and Wheat Improvement Center). (2009). Annual Report. Effective Grain Storage for Better Livelihoods of African Farmers Project (p. 35). CIMMYT-Nairobi, Kenya.

CIMMYT (International Maize and Wheat Improvement Center). (2011). Completion Report June 2008 to February 2011. Effective Grain Storage for Better Livelihoods of African Farmers Project (p. 35). CIMMYT-Nairobi, Kenya.

De Groote, H., Kimenju, S., Likhayo, P., Kanampiu, F., Tafere, T., \& Hellin, J. (2013). Effectiveness of hermetic systems in controlling maize storage pests in Kenya. Journal of Stored Products Research, 53, $27-36$. https://doi.org/10.1016/j.jspr.2013.01.001

FAO. (2008). Household metal silos, key allies in FAO's fight against hunger by Agricultural and Food Engineering Technologies Service (AGST). FAO of the United Nations, Rome, Italy. Retrieved August 8, 2012, from http://typo3.fao.org/fileadmin/user_upload/ags/publications/silos_E_light.pdf

GenStat. (2011). GenStat for Windows $14^{\text {th }}$ Edition. VSN International, Hemel Hempstead, UK.

Gwinner, J., Harnisch, R., \& Muck, O. (1996). Manual on the prevention of post-harvest seed losses (p. 294). Post-harvest project, GTZ, D-2000. Hamburg, FRG.

Hellin, J., \& Kanampiu, F. (2008). Metal silos and food security in El Salvador. Appropriate Technology, 35, 69-70.

Kimenju, S. C., De Groote, H., \& Hellin, H. (2009). Preliminary Economic Analysis: Cost effectiveness of the use of improved storage methods by small scale farmers in east and southern Africa countries (p. 17). CIMMYT (International Maize and Wheat Improvement Center).

Mallya, G. A. (1992). Prostephanus truncatus (HORN), the larger grain borer (LAB), and its control in Tanzania. In: Implementation of and further research on biological control of the larger grain borer. Proceedings of an FAO/GTZ Coordination meeting. Lome, Togo.

Murdock, L. L., Margam, V., Baoua, I., Balfe, S., \& Shade, R. E. (2012). Death by desiccation: Effects of hermetic storage on cowpea bruchids. Journal of Stored Products Research, 49, 166-170. https://doi.org/ 10.1016/j.jspr.2012.01.002

Musa, A. K., Oyerinde, A. A., \& Owolabi, F. O. (2009). Evaluation of the Efficacy of Mixed Leaf Powders of Vernonia amygdalina L. and Ocimum gratissimum Del. Against Callosobruchus maculatus (F.) (Coleoptera: Bruchidae). Academic J. Entomol., 2(2), 85-87.

Navarro, S., Donahaye, E. J., \& Fishman, S. (1994). The future of hermetic storage of dry grains in tropical and subtropical climates. Proceedings of the 6th International working Conference on Stored-Product Protection, April 17-23, 1994, Canberra Australia (Vol. 1, pp. 130-138). 
Pattinson, I. (1970). Grain Storage at Village Level. FFHC Action Program Report TAN/II. FFHC/FAO, Rome.

POSTCOSECHA. (2011). In M. Fischler, R. Bokusheva, R. Finger, Y. Marín, F. País, K. Pavón, \& F. Pérez (Eds.), 5 Year Ex-Post Impact Study: POSTCOSECHA Programme Central America, Final Report March 2011 (p. 128). Swiss Agency for Development and Cooperation, Switzerland.

Quezada, M., Moreno, J., Vazquez, M., Mendoza, M., Mendezalbores, A., \& Moreno, M. E. (2006). Hermetic storage system preventing the proliferation of Prostephanus truncatus Horn and storage fungi in maize with different moisture contents. Postharv. Biol. Tech., 39(3), 321-326. https://doi.org/10.1016/j.postharvbio. 2005.10 .004

Ragai, H., \& Loomis, W. E. (1954). Respiration of maize grains. Plant Physiology, 29, 49-55. https://doi.org/ 10.1104/pp.29.1.49

Reuss, R., \& Pratt, S. (2001). Accumulation of carbon monoxide and carbon dioxide in stored canola. Journal of Stored Products Research, 37, 23-34. https://doi.org/10.1016/S0022-474X(99)00060-0

Reuss, R., Damcevski, K., \& Annis, P. C. (1994). The impact of temperature, moisture content, grain quality and their interactions on changes in storage vessel atmospheres. In E. Highley, E. J. Wright, H. J. Banks, \& B. R. Champ (Eds.), Stored Products Protection, Proccedings of the $6^{\text {th }}$ Inter. Working Conference on Stored Products Protection (Vol. 1, pp. 178-182). Canberra Austratlia: CAB International.

Sambarashe, M., Chitamba, J., \& Sipiwe, G. (2013). Screening of stored maize (Zea mays L.) Varieties Grain for Tolerance against Maize Weevil, Sitophilus zeamais (Motsch.). International Journal of Plant Research, $3(3), 17-22$.

Songa, W., \& Irungu, J. (2010). Post-harvest Challenges to food security in Kenya. Republic of Kenya Ministry of Agriculture.

Tefera, T., Kanampiu, F., De Groote, H., Hellin, J., Mugo, S., Kimenju, S., ... Marianne, B. (2011a). The metal silo: An effective grain storage technology for reducing post-harvest insect and pathogen losses in maize while improving smallholder farmers' food security in developing countries. Crop Protection, 30, 240-245. https://doi.org/10.1016/j.cropro.2010.11.015

Tefera, T., Mugo, S., \& Likhayo, P. (2011b). Effects of insect population density and storage time on grain damage and weight loss in maize due to the maize weevil Sitophilus zeamais and the larger grain borer Prostephanus truncatus. African Journal of Agricultural Research, 6, 2249-2254.

Tefera, T., Mugo, S., Tende, R., \& Likhayo, P. (2010). Mass rearing of stem borers, maize weevil, and larger grain borer insect pests of maize. CIMMYT: Nairobi, Kenya.

USDA. (2009). Complete guide to home canning. Principles of home canning. Retrieved March 28, 2015, from http://www.nchfp.uga.edu/publicationslpublication_usda.html

Whittle, C. P., Waterford, C. J., Annis, P. C., \& Banks, H. J. (1994). The production and accumulation of carbon monoxide in stored grain. Journal of Stored Products Research, 30, 23-26. https://doi.org/10.1016/ 0022-474X(94)90269-0

\section{Copyrights}

Copyright for this article is retained by the author (s), with first publication rights granted to the journal.

This is an open-access article distributed under the terms and conditions of the Creative Commons Attribution license (http://creativecommons.org/licenses/by/4.0/). 